\title{
Teaching Business English Course: Incorporating Portfolio Assessment-based Blended Learning and MOOC
}

\author{
YANG Xiao, GAO Hao \\ School of Foreign Languages, Wuhan University of Technology, Wuhan, P.R.China, 430070
}

\begin{abstract}
Recent years have witnessed the growth of the popularity of open online learning platforms in China's colleges and universities. This not only promotes the change of teaching concept and the reform of teaching methodology, but also provides a broad new opportunity for the teaching resource integration between universities in China and the prestigious universities in the world. However, with MOOC's booming and spreading, educators and teachers have also found its limitations during the course of teaching and learning. This paper focuses on the design and the application of the integration of blended learning model and MOOC in Business English Course by selective use of the Open Course Ware of MIT Management School. With the advanced e-portfolio assessment as the standard for students' achievement, it aims to reveal that the proposed model can trigger students' study interest and cultivate their autonomous study, corporate learning as well as creative thinking ability.
\end{abstract}

Keywords: MOOCs, Blended learning, Portfolio, Business English

\section{Introduction}

Recent decades have witnessed the rise and boom of MOOCs in higher education. Massive Open Online Courses, or MOOCs, boasts the followings features: no admission requirements for learners, large scale of learner groups and disciplines, aggregation of high-quality educational resources and openness. Ahmed (2015) claims that MOOCs have the potential to charter new courses for higher education landscapeby fostering a brand-new ecological environment of education based on advanced educational technology. MOOCs also offer a wider range of choice and disciplines for learners regardless of locations without any prerequisites or admission requirements. In addition, MOOCs accelerate the movement toward a vision of lifelong and on-demanding learning for full-time employees or those who have taken a break from formal education (Kop, Fournier, \& Mak, 2011).

The year of 2012, known as the Year of the MOOC, marked a milestone of MOOCs development as the three major MOOC platforms, namely Coursera, Udacity and edX, came online and saw rapid growth of enrollments. These courses mainly consisted of five-to-ten-minute video lectures, exercises, discussion forum, reading materials. The year of 2013 witnessed the expansion and struggle of MOOCs. On the one hand, MOOCs platforms sprouted like weeds throughout the world. In Europe, UK initiated Futurelearn, Germany opened

YANG Xiao, Master of Arts, Professor, School of Foreign Languages, Wuhan University of Technology. GAO Hao, Postgraduate Student, School of Foreign Languages, Wuhan University of Technology. 
Iversity and the European Union started OpenupEd. EduKart came online in India, Schoo came into being in Japan, and Open2Study was established in Australia. In China, platforms including IMOOC, ICourse163 appeared and developed briskly. On the other hand, the wild growth of MOOCs platforms raised concerns of teachers and universities. On May 23, 2013, in a joint letter sent to the Dean of Harvard's Faculty of Arts and Sciences, 58 professors proposed to set up a special steering committee to address edX-related problems, which was the first time that elite professors from a top university had challenged MOOCs in unison. American Professors'major worries are as follows: Firstly, what will be the unique significance of classroom teaching and examination considering that everyone has the access to high-quality online education resources? Secondly, once MOOC became prevailing, there would be sharp disparity between well-funded schools and poor-funded schools since students in the former schools have more opportunities to enjoy face-to-face exchanges with professors while students in the latter ones have to take those online courses because their schools tend to employ relatively inexpensive MOOCs courses (Guo, 2014).

Despite the rapid expansion of MOOC in China, Chinese researchers felt headwinds during the application of this new learning model. To begin with, it is a formidable challenge for students to maintain learning motivation from beginning to end. The Internet enables every learner to select courses and make online discussions in a MOOC platform regardless of time and place.The freedom embedded in Internet determines that learning activities in MOOC platformare regulation-free and self-motivated. Without instructions or guidance, self-learners are inclined to give up online learning process, a tendency evidenced by a research that only $7 \%-9 \%$ of MOOC learners completed and passed their courses (Parr, 2014). Secondly, language is the barrier when Chinese students learn courses in world-renowned MOOC platforms like Coursera, Udality and edX, since not all Chinese students are excellent enough to understand the contents in English. Language problem has become tiger in the road when Chinese students aspire to acquire high-standard online resources. Thirdly, due to differences in politics, culture, history and ideology between China and the West, some courses, especially those courses involving sensitive topics are inappropriate for Chinese students to learn. Other limitations of MOOCs include pedagogical problems regarding assessment and feedback as well as the lack of interactions between learners and teachers. On addressing these limitations, the engagement of teacher is highly required. In fact, some scholars have put forward a new MOOCs modelin a blended-learning approach that aims at bringing in-class interactions and online learning components together. As far as learning assessment and feedback are concerned, a new type of assessment tool known as e-portfolio is employed.

\section{MOOCs and Blended Learning}

Though embracing abundant educational resources, MOOCs are not suitable for every single learner, especially for those who are weak in self-control and self-discipline. Traditional face-to-face teaching plays an indispensable role in cultivating students' self-initiative. To this end, many Chinese universities embark on their reform by integrating MOOC resources and traditional teaching model, giving rise to blended learning model. In a broad definition, blended learning could be seen as the continuum between traditional face-to-face teaching and pure online distance courses (Watson, 2008). Some researchers (c.f. Fisher, 2014) point out that teachers' workload in a blended learning model is much smaller than their standard workload since lecture videos, assignments and other learning materials are already produced and can be used for several times. However, this 
raises new questions about the role of teachers in blended learning. Bruff et al (2013) find that teachers' focus shift in blended learning. Teachers attach more importance to the design of MOOC elements and delivery of knowledge in order to motivate students. As He Kekang (2004) puts it, "Teachers in blendedlearning model should play a pivotal role in guiding, enlightening and supervising students while students should be proactive, positive and creative in the course of learning” (p. 1). "Blending” not only bears the meaning of combining online learning and face-to-face learning, but also emphasizes the integration of various teaching models, ultimately constituting a combination of educational resources, learning styles and learning environments.

\section{Implementing Blended Learning in the Course Business English}

\subsection{Participants and Course Objectives}

The course Business English covers the contents of Foreign Business English and Business English and Communication, aiming at teaching students communication skills within business context and foreign trade English correspondence. After learning the course, students are expected to foster strong communication ability in diverse situations, understand favorable communication strategies and approaches, articulate idea politely and appropriately in business context andhorn writing skills in business correspondence. The participants of this course involve over 200 students from Wuhan University of Technology (WUT) who take the course for the first time.

\subsection{Course Design and Implementation}

The main platform this course employs is WUT MOOC platform, which is closely connected to the campus Learning Management System (LMS). There are several modules within the platform. (1) Curriculum module enables teachers update course information, assessment plan and rubrics. (2) Teaching module helps teachers give and check assignments, hold online test, discussions, share resources, check learning record, record classroom performance and conduct other managerial activities. (3) Reflection module enables editing and sharing learning notes and diaries for the improvement of teaching and learning. (4) Portfolio module supports the establishment of e-portfolios. As WUT makes a stride in utilization of global MOOC resources, it has purchased service and courses from many global MOOC platforms, among which MIT OCW (Open Course Ware) is one of the most valuable platforms. MIT, the pioneer in the field of MOOC application, now possesses materials from 2400 courses with over 300 million visitors in its OCW platform. The course Management Communication from Sloan School of Management of MIT is relevant to the Business English course, and it introduces high-quality reading materials, valuable assessment rubrics, excellent assignments and other useful materials, so the authors selectit as a reliable supplementary material source in the teaching process.

The core idea of this course design is transforming traditional learning process into a new model featuring pre-class knowledge acquisition, in-class teaching and after-class development.

\subsubsection{Pre-class knowledge acquisition}

Before class, students are expected to watch lecture videos in WUT MOOC platform and read materials that were selected by the teacher from MIT Management and Communication course, followed by some quizzes. Then they have to raise their own questions and bring them to the classroom. The teacher will check the students' performance, which accounts for $10 \%$ of their final scores. Sometimes, students are asked to prepare presentations, reports or simulated dialogues for the coming face-to-face class. 


\subsubsection{In-class teaching}

Blended learning requires efficient face-to-face teaching process. During first part of in-class teaching, the teacher guides students, introduces cross-cultural context, explains vague concepts and difficulties. After explaining key and important points, the teacher encourages students to pool their wisdom.Students are welcome to ask questions they have already prepared before class. They will be graded according to the creativeness, depth, breadth and practicability of their questions.

During the second part of the class, the floor is open to students. Take Unit 4: Report as an example, students are supposed to make a short group presentation. After finishing the report, there will be comments and challenge from other groups - once the defensive group fails to answer challenges, the challenging group gets more points. In this way, students are motivated and inspired in a cooperative and competitive environment. Before ending the class, the teacher comments on the works of different groups and gives suggestions.

\subsubsection{After-class development}

After class, students are supposed to improve their works according to the comments from the teacher and other groups and update in the platform. For those who pursuit the best grades, works can be submitted more than once until they are satisfied with their scores. Reflection module allows students to ask questions. Those frequently asked questions would be put into "Most-asked questions” section. Besides, students can also upload their notes for exchanges. By making a comparison between their notes and the teacher's, students are able to improve their own notes. The teacher leaves assignments for students to finish in groups, with forms ranging from reading reports, interviews to debates, through which variety of assignments are significantly enriched. Before doing their homework, students will get a rubric according to the different content of assignment. The teachers will also grade students according to the same rubric.

\section{E-portfolio-Based Assessment}

Instead ofutilizing traditional summative evaluation, formative evaluation is adopted in the course. Summative evaluation, normally conducted at the end of a semester, regards final examination scores as the sole evaluation criterion, which stifles students' passion and suppresses their initiative. Although summative evaluation remains an inseparable part in teaching evaluation, it fails to track the whole learning process and ultimately fails to make accurate teaching evaluation. Consequently the teacher applies formative assessment by collecting students' work in the learning process to make comprehensive assessment. As an important approach to formative assessment, portfolio assessment highlights that students should be responsible for their own learning process (Hewett, 2004). As a result, teachers should be the guidewhile students the real planers and implementers of their learning process.

A learning portfolio refers to an assessment tool purposefully collocating learning processes over a period in a way that reflects academic achievements, including evidence of progress, reflective thinking, learning outcomes, and so on (Chang, Liang, \& Chen, 2013). Traditionally, portfolios are in written form such as essays or papers. However the advance of science and technology makes more various leaning materials become reality. Students now can submit videos, recordings, photos.

The portfolio assessment mainly follows two steps-developing assessment rubrics anddetermining assessment procedure. 


\subsection{Developing Assessment Rubrics}

Rubrics are a set of items that would be used for evaluating students' portfolios. The value of portfolio substantially lies on its scientificity and validity (Zhou, 2011). There should be a unified standard otherwise students may get confused about learning contents and learning process. It is worth noting that rubrics should be flexible while maintaining a basic standard. In other words, rubrics should be specific and clear to meet demands of different occasions and assignments. For example, the rubrics of a group report are different from that of simulated dialogues in the course Business English. While designing rubrics, the teacher upholds basic standards on homework or assignments and discusses detailed items with students. Produced by concerted efforts between students and the teacher, rubrics are more likely to be followed and implemented. During the discussion process, students cultivate their communication and judging ability. Table1 shows the rubrics for oral presentation which is the outcome of teacher-student discussion.

Table 1

Rubrics for Oral Presentation

\begin{tabular}{|c|c|c|c|}
\hline Criteria & Highe & Medium & Low \\
\hline Eye contacts with the audience - & Frequent eye contacts(8-10pts) & Medium eye contacts(5-7pts)et & Little eye coatacts $(0-4 p t s)$ ? \\
\hline $\begin{array}{l}\text { Body language ( proper body } \\
\text { languzge or improper body } \\
\text { language including quivering } \\
\text { hands, shaking legs, playing } \\
\text { with hast ete)- }\end{array}$ & Natural body actions(8-10pts) & $\begin{array}{l}\text { Not so natural, a little bit } \\
\text { nervous }(5-7 \mathrm{pts})\end{array}$ & $\begin{array}{l}\text { Very nervous without natural } \\
\text { actions( } 0-4 \mathrm{pts}) \text { ? }\end{array}$ \\
\hline $\begin{array}{l}\text { Fluency of the speech (pace of } \\
\text { speech, modal particles like } \\
\text { "sh"." "hmm"., "uh", ste)? }\end{array}$ & $\begin{array}{l}\text { Very fluent with proper } \\
\text { speed(8-10pts) }\end{array}$ & $\begin{array}{l}\text { There are a few modal particles } \\
\text { but the speed is ok (5-7pts) }\end{array}$ & $\begin{array}{l}\text { There are lots of modal } \\
\text { particles and the speed is either } \\
\text { too fast or too slow( }(0-4 \text { pts })\end{array}$ \\
\hline Voice of the speaker & Loud and clear(8-10pts) & Not loud/aot clear(5-7pts) & Neither loud nor clear(0-4pts) \\
\hline Content of the speecb & $\begin{array}{l}\text { Logical, interesting and } \\
\text { attractive(8-10pts) }\end{array}$ & $\begin{array}{l}\text { The topic is clear but there is } \\
\text { room for improvement }(5-7 \mathrm{pts})\end{array}$ & $\begin{array}{l}\text { The speech is confusing and } \\
\text { bering }(0-4 \text { pes })\end{array}$ \\
\hline
\end{tabular}

\subsection{Determining Assessment Procedure}

Basically, portfolio assessment incorporates self-assessment, peer assessment and teacher assessment, among which self-assessment takes the most significant weight, because only through self-assessment can a student gradually foster a sense of ownership and enhance self-initiative. Peer assessment provides a vital platform for discussion on equal-footed basis while teacher assessment aims at finding shining points of students' performance. In the course Business English, students set up learning plans and goals in their portfolios and take part in teaching process through self-assessment and peer assessment. The teacher and the teaching assistants track the implementation of the students learning goals and give advice and comments.

During the implementation of portfolio assessment in Business English, the teacher acts as a facilitator instead of a commanderto foster student-centered classroom atmosphere. If the teacher imposes too much on students, portfolio will become a burden instead of an incentive for students. At the beginning of the semester, the teacher tells studentshow to use portfolio module in WUT MOOC platform and requiresthem to set up their own learning goals and plans. During the semester, students always receive comments and suggestions from the teacher and peers. By uploading their assignments in various forms to their e-portfolio, students can observe their own learning path at any time.At the end of the semester, a questionnaire on the students shows that they are satisfied with this model while recognizing their progress in English proficiency, teamwork and creativity. 


\section{Conclusion}

The rapid development of MOOCs opens up new horizons for both learners and teachers. However, teaching and learning quality still remain dissatisfactory. To deal with the limitations of MOOCs, blended learning model is a good option, featuring teacher-student interactions, student-centered classroom and online learning. Given that one of the greatest weaknesses of MOOCs is the lack of effective assessment and feedback, e-portfolio assessment in the context of blended learning provides a desirable solution. By setting up an e-portfolio, teachers are able to perceive students' learning achievements while students self-initiative can be significantly enhanced. So far, from the practice of Business English teaching, the model incorporating of portfolio assessment-based blended learning and MOOC is an ideal approach.

\section{References}

Bruff, D. O., Fisher, D. H., \& Mcewen, K. E., et al. (2013). Wrapping a MOOC: Student perceptions of an experiment in blended learning. Journal of Online Learning \& Teaching, 9(2), 187-199.

Chang, C. C., Liang, C., \& Chen, Y. H. (2013). Is learner self-assessment reliable and valid in a web-based portfolio environment for high school students? Computers \& Education, 60(1), 325-334.

Fisher, D. H. (2014). Leveraging AI teaching in the cloud for AI teaching on campus. Ai Magazine, 35(3), 98-100.

Guo, Y. J. (2014). The current situation, dilemma and future of MOOCs. Journal of Higher Education Management, 8(4), 41-48. (In Chinese)

He, K. K. (2004). Learning the new development of educational technology from the perspective of blending learning. E-education Research, (3), 21-31. (In Chinese)

Kop, R., Fournier, H., \& Mak, J. S. F. (2011). A pedagogy of abundance or a pedagogy to support human beings? Participant support on massive open online courses. International Review of Research in Open \& Distance Learning, 12(7), 74-93.

Parr, C. (2014) MOOC completion rates below $7 \%$ [EB/OL]. Retrieved from http://www.time-shighereducation.co.uk/news/mooc-completionrates-below-7/2003710.

Watson, J. B. (2008). Blended learning: The convergence of online and face-to-face education. Promising practices in online learning. North American Council for Online Learning, 18.

Yousef, A. M. F., Chatti, M. A., \& Schroeder, U. et al. (2015). A usability evaluation of a blended MOOC environment: An experimental case study. International Review of Research in Open \& Distributed Learning, 16(2), 69-93.

Zhou, D. D. (2011). Portfolio assessment and its current situation in China. Education Assessment and Evaluation, (7), 21-24. (In Chinese) 